biplane of 1903 and the Vickers-Vimy trans-Atlantic aeroplane of 1919. A Blériot monoplane, type XI (Cross-Channel type), was flown by M. Leon Molon at Doncaster in October 1909, where it gained a height record. It has a speed of about 40 m.p.h. and is similar to the machine in which Louis Blériot made his historic crossing of the Channel from the French coast to Dover on July 25, 1909. Another Blériot (type XXVII) with a speed of 80 m.p.h. is the original Gordon Bennett Cup racing machine which Alfred Leblanc flew at Long Island, U.S.A., in 1911. These machines represent the aeroplane in an early stage of its development as a mode of transportstill experimental and confined mainly to exhibition flying and competitions. No degree of standardization had then been reached, and the aeroplane was not regarded as a really proved instrument; the position was still one of uncertainty as to the future of flight. The advent of the Great War in 1914 had, however, a profound effect on the aeroplane, and it produced an intensive development which may be estimated from the example of a Sopwith "Camel" of 1917, a famous fighter scout which was the first aeroplane to be fitted with twin synchronized guns and had a performance undreamt of in 1909, namely, a speed of 113 m.p.h. at $10,000 \mathrm{ft}$. and a climb to $5,000 \mathrm{ft}$. in five minutes. An actual wartime Fokker D.VII fighter, which belonged to Jadgstaffel 71 of the German Air Force, also shows the rapid development of the aeroplane for military uses which resulted from the stimulus of war. Another famous aeroplane of the War period is the Vickers-Vimy bomber, which made the first non-stop flight across the Atlantic on June 14-15, 1919, piloted by the late Sir John Alcock with Sir Arthur Whitten Brown as navigator, now exhibited in Gallery VI.

\section{An Early Wet-Plate Folding Camera}

VALUABLE additions to the photography collections at the Science Museum, South Kensington, include a complete outfit for the wet-plate process, of date 1854, presented by His Grace the Duke of Devonshire. The outfit comprises a folding wood camera by Ottewill, a sensitizing bath, and a complete set of chemicals and reagents in its original leather carrying case. These objects are all of considerable interest as showing the types of apparatus and accessories necessary for "photography in the field" in the early days of the "photographic art".

\section{Water Pollution}

THE forty-sixth Bedson Lecture was delivered by Sir Robert Robertson on May 8 in King's College, Newcastle-upon-Tyne. Sir Robert confined himself to two recent investigations connected with the subject of water pollution. The first of these concerns the pollution problems of the River Tees. A thorough biological and chemical survey of this river has been carried out. This has shown that, whilst the river is unpolluted until its union with the Skerne, the entry of sewage from Darlington in this tributary causes appreciable pollution of the lower reaches. In the estuary, the condition of the river is rendered much worse by industrial refuse containing cyanide. As a result of the investigation, the sewage disposal system of Darlington has been improved, and several undertakings upon Teeside have modified their plants, so that cyanide does not enter the river. With regard to the second topic-the disposal of milk factory waste-Sir Robert said that diluted milk, on account of its easily oxidizable nature, is a potent fish poison. As a result of its consistency, the refuse is difficult to treat by ordinary filtration methods, and success was first obtained by a modified activated sludge process. However, better results have been obtained by use of two filters in series. The refuse is passed first to one filter, $A$, and thence to the second, $B$. When $A$ shows signs of clogging, usually in about three weeks, the direction of flow is reversed, that is, the liquid passes first to $B$ and then to $A$. Filter $A$ then recovers, and in due course the direction of flow is again reversed, and so on.

\section{A Utilitarian Classification of Fragmentary Fossils}

IT is generally understood that the generic and specific names given to fossils cannot often be defined so precisely as those given to existing organisms. It is also recognized that the classification of extinct genera into families and orders is not always satisfactory. At the same time, readily distinguishable fossil fragments with definite characters need names, because they can frequently be used to determine the geological age of the rocks in which they occur. Such names are now proving especially useful in the microscopical study of sponge spicules, holothurian and echinoid spicules, plates of star-fishes and crinoids, conodonts, fish teeth and scales, otoliths, pollen grains, and other fragments which denote special conditions or mark horizons in series of rocks. The names are always in the Linnean form, and the so-called genera and species are grouped into so-called families and orders on the Linnean plan. Prof. Carey Croneis, in a recent letter to Science (89, 314 ; April 7,1939$)$, and in an earlier article in the Journal of Geology (46, 975-984; Oct.-Nov. 1938 ), points out that this classification is misleading. For the various grades he proposes adopting the terms used in the old Roman army : for species he would use 'centuria'; for genus, 'manipulus'; for family, 'cohors'; and for order, 'legio'. He would thus distinguish a utilitarian classification from one which has the appearance of being natural.

\section{Prevention of Road Accidents}

The report of the Select Committee of the House of Lords, appointed to consider what steps should be taken to reduce the number of casualties on the road, is discussed in Roads and Road Construction of May. It is pointed out that since 1910 the number of vehicles on the roads has increased twenty times, and in addition there has been a marked increase of mileage run per vehicle. During the same period the increase in road production is only about two per cent. The Committee is unable to accept the con- 